\title{
Participación de la mujer en la edición de una revista literaria en los años sesenta del siglo XX en México: El Rehilete
}

\author{
Arturo Texcahua Condado*
}

Resumen:

A pesar de que El Rebilete no fue una publicación que se asumiera como feminista y que en cambio desde sus inicios se presentó como una revista de perfil literario, estamos ante un proyecto planeado y construido por mujeres, cuya contribución además se hizo patente en su interés por publicar a autores jóvenes y desconocidos, durante la década que va de 1961 a 1971. Todo ello durante los años en que el feminismo reivindicaba derechos ciudadanos luego de años de marginación por parte de su contraparte ideológica, el machismo. Por todo ello puede decirse que El Rebilete contribuyó a la necesaria transformación de la cultura nacional de aquellos años, al mismo tiempo que en sus páginas, como ocurre normalmente en las revistas literarias, se definían ideas, afinidades e intereses a propósito de la formación de grupos y generaciones; de ahí que el estudio de estas publicaciones resulte primordial para entender fenómenos muy complejos que, en el caso de El Rehilete, cobran gran importancia, como el hecho de que la mujer desempeñó un papel protagónico, con frecuencia escamoteado en los recuentos históricos de ese y otros períodos. De ahí que la lectura de esta revista pueda contribuir al dibujo de la imagen de la mujer intelectual de los sesenta.

* Universidad Autónoma del Estado de México. 
Palabras clave:

Feminismo, revistas literarias, editoras, mujer intelectual.

El Rebilete fue una revista literaria concebida y hecha por mujeres entre 1961 y 1971. Esos dos hechos -lo literario y lo femenino- le confieren un especial significado dentro de la literatura mexicana. Hablo de los años en los que iniciaba un feminismo que exigía cambios como respuesta a miles de años de subordinación y de marginación histórica.

Aunque este esfuerzo editorial no fue el primero, y aunque las editoras nunca manifestaron que El Rehilete tuviera un perfil feminista, además del estrictamente literario que sí expresaron abiertamente desde el primer número, hay una evidente aportación que adquiere mayores dimensiones cuando, además, se observa que la publicación fue espacio de jóvenes escritores que en ese momento iniciaban su despunte en las letras mexicanas. Por ello, queda claro que contribuyó en la transformación que, por todos lados y en muchos sentidos, vivió la cultura del país en ese momento.

Desde el siglo XIX las revistas literarias han servido en Latinoamérica para dar a conocer parte de la producción literaria de escritores y han permitido que afinidades, ideas y posiciones se reúnan propiciando la formación de grupos, la integración de generaciones y el establecimiento de posicionamientos. En general, se les puede considerar como imprescindibles para un conocimiento profundo de la literatura de los países latinoamericanos. Ciertamente, en México no se entiende con cabalidad la literatura sin revisar antes el papel jugado por las revistas literarias.

Publican en El Rehilete jóvenes, maduros y grandes escritores mexicanos, artistas plásticos connotados, además de las propias editoras. En sus diez años de vida (lo que demuestra por sí solo una perseverancia tenaz) se editan 36 números, divididos en tres periodos, que terminan en abril de 1971. De este modo, la revista reúne, como una antología de la década de los sesenta, valiosos e interesantes poemas, fragmentos de novelas, cuentos, entrevistas, reseñas, ensayos de literatura y de arte, textos de teoría literaria y de teatro, 
testimonios y artículos, muchos de los cuales fueron integrados a libros posteriormente.

Lo anterior prueba el afán de las mujeres por rescatar el lugar que la historia hecha por el hombre le había quitado en todos los ámbitos de la cultura, así como evidencia otros propósitos empresariales, laborales, sociales y literarios. Igualmente, El Rehilete rescata los intereses y las preferencias literarias de una época sacudida por cambios y nuevas ideas.

Si bien es cierto que las editoras nunca se reconocieron como feministas, el carácter transgresor de su proceder las ubica entre aquellas mujeres que incursionaron, con su participación intelectual, en un campo todavía restringido por los hombres.

No obstante que no haya sido la primera ocasión en la historia literaria mexicana, las mujeres de El Rehilete, como escritoras, como editoras y como empresarias, encabezaron una provocación dirigida hacia los hombres, a quienes demostraron con la edición de la revista que ellas también podían hacer una publicación periódica y la podían hacer bien. Igualmente con la edición de El Rehilete provocaron a otras mujeres, en el sentido de que provocar también significa inducir a alguien a que ejecute algo; lo que hicieron dio ejemplo a otras mujeres, y con ello indujeron a realizar lo mismo.

Además de conseguir, reunir y seleccionar los textos que se publicarán, el grupo de editoras incorpora sus propios textos. En estos se plantea descubrir inclinaciones por géneros, temas y estilos. En sus editoriales, en sus críticas, en su discurso hay mucho de ellas y de sus intereses; está la mujer intelectual de aquel momento. También hay diferencias; una huella, una marca propia que fijaron a pesar de haberse sujetado a los términos de un quehacer literario cuyas características eran las dictadas por un paradigma masculino, y no obstante su decisión de intentar identificarse con ellos, de confundirse. La revista les sirve para crecer, como mujeres y como escritoras de los sesenta.

Las principales rehileteras fueron nueve: Beatriz Espejo, Carmen Rosenzweig, Margarita Peña, Elsa de Llarena, Carmen Andrade, Lourdes de la Garza, Blanca Malo, Margarita López Portillo y Thelma Nava. Rosa María Galindo, Guadalupe de León, Esther 
Ortega, Guadalupe González Violante, Antonieta Merino, Yolanda Argudín son personajes casi incidentales que también integran el directorio con funciones más bien administrativas: no publican nada. Carmen Andrade se integra al equipo a partir del número 7 y saldrá hasta el final de la segunda época. Margarita López Portillo se integra al inicio de la segunda época. Nava sale al poco tiempo del directorio porque editará Pájaro Cascabel, la revista que elaborará con Luis Mario Schneider, y el apoyo de su esposo, Efraín Huerta. Destaca el hecho de que en la corrección queden las dos universitarias: Margarita Peña y Blanca Malo. Las nueve principales rehileteras colaboran en su edición y publican en la revista, buscan eso.

Desde el número 9, dos años y medio después de que iniciara el proyecto, el directorio se simplifica. Bajo la palabra directorio se relacionan los nombres de las rehileteras sin cargo específico, como se había hecho en los ocho números anteriores, y en el siguiente orden: Beatriz Espejo, Carmen Rosenzweig, Margarita Peña, Blanca Malo, Elsa de Llarena, Lourdes de la Garza y Carmen Andrade. Así cierran el año 1963. Al siguiente número, el 10, Blanca Malo ya no estará, se habría casado con el doctor Manuel Alcalá, y le dio prioridad a su matrimonio como ella misma lo confiesa. El directorio no tendrá cambios hasta el número 17, el primero de la segunda época, en la que ya no aparecen tres de las primeras rehileteras: Beatriz Espejo (que fue a estudiar a Estados Unidos), Margarita Peña (que tuvo un hijo), y Lourdes de la Garza (también casada y con mucho trabajo publicitario, principalmente el derivado de las campañas de promoción del detergente Fab). Ante estas mermas, las tres restantes aceptan con gusto la presencia de Margarita López Portillo, a partir del número 19 y seis meses después de quedarse solas. El directorio se moverá un poco en el número 22, cuando Beatriz Espejo encabeza un número extraordinario dedicado a los siete pecados capitales. El nombre de Espejo aparecerá a un lado de dos palabras: Directora huésped. La directora fundadora se ha convertido en una invitada. También Espejo dirige el número dedicado a las virtudes teologales, pero no es mencionada en el directorio. El número 27, en junio de 1969, verá otro cambio. Seguirán las cuatro, pero a un lado del nombre de Carmen Rosenzweig se verá la 
palabra responsable. Esta situación se sostendrá en los próximos dos números, que son además con los que se cierra la tercera época. A partir del número doble 30-31 solo quedarán dos de las rehileteras: Carmen Rosenzweig y Elsa de Llarena, bajo la palabra directiva, y debajo de las palabras consejo de redacción harán acto de presencia los nombres de dos jóvenes poetas: Mariano Flores Castro y Mario del Valle. Esta situación solo cambiará en el último número de la revista, el número doble 35-36, cuando debajo de la palabra dirección vendrán los nombres de las dos mujeres rehileteras y de los dos varones poetas.

Los pormenores antes narrados sobre el desarrollo del directorio hacen ver que en el directorio únicamente Carmen Rosenzweig y Elsa de Llarena se mantuvieron dentro de la dirección del proyecto hasta el final. Un dato que hace sospechar reclamos al interior del grupo en el trabajo directivo se publica en el número 22, casi oculto en la p. 71, y dice: "De acuerdo con el espíritu del [sic] Rehilete, y a fin de darle en lo que cabe todos los giros posibles, la Dirección cree conveniente (y esto es válido desde el número anterior), que los nombres que la integran vayan girando. C. R."

Los puntos de confluencia que reunirán a las mujeres que forman el grupo de El Rehilete son tres: la Facultad de Filosofía y Letras de la Universidad Nacional Autónoma de México, donde estudian Margarita Peña, Beatriz Espejo y Blanca Malo; el Centro Mexicano de Escritores, donde son becarias Carmen Rosenzweig, Lourdes de la Garza y Thelma Nava; y el taller literario de Juan José Arreola, en el que participan Carmen Rosenzweig y Elsa de Llarena.

Los lazos de amistad de una acercan a las otras. Además de los pasillos y las áreas comunes de la Facultad de Filosofía y Letras, se reúnen en cafés como muchos lo hacían entonces o en la casa de Elsa de Llarena, donde se respiraba libertad, además de ser un espacio céntrico y agradable, gracias al gusto de una mujer que estaba divorciada. Otro rasgo en común entre Carmen Rosenzweig, Elsa de Llarena y Beatriz Espejo es que habían sido editadas por Juan José Arreola. Carmen Rosenzweig había sido becaria del Centro Mexicano de Escritores en 1957. En la colección de Cuadernos del Unicornio, en 1956, Arreola le había publicado El pueblo. Del mismo 
modo, en la colección Los Presentes le publicaría El reloj, en 1956, y la novela 1956, en el año 1958. Por su parte, Elsa de Llarena publicaría también en los Cuadernos del Unicornio el libro Prosas, en 1958. Con La otra hermana, Beatriz Espejo iniciaría su trabajo como escritora y también en la colección Cuadernos del Unicornio, igualmente en 1958. Es evidente la estrecha relación de las rehileteras con Juan José Arreola. Por ello, no es de extrañar la rigurosa postura que las uniera sobre el cuidado de la forma, la revisión y perfección de los textos, principios que enseñaba el jalisciense en su taller, además de estar familiarizadas con la crítica directa como método de revisión en el taller de Arreola y en el Centro Mexicano de Escritores. Quizá, del mismo modo, ello explique la obsesión de las rehileteras por la calidad como bandera, que insistentemente subrayaron en los editoriales de la revista. Cabe señalar que ellas serán, además, las pioneras de un trabajo que después se volverá una rutina obligada para los escritores noveles: participar en un taller literario.

De las relaciones de cordialidad estas compañeras de taller pasaron a las de amistad y a la planeación de proyectos comunes, como en este caso, la publicación de una revista literaria. Como generación, las une, en principio, precisamente el hecho de ser mujeres, y lo que ello conlleva. Además, tienen en común su gusto por la literatura, por la escritura y su condición sociocultural y económica. Sus edades y ocupaciones son diversas. Carmen Rosenzweig (19262010) y Elsa de Llarena (1924-1993) son las mayores, rebasan los treinta años en ese momento. Las otras son veinteañeras. Esa diferencia de edades las vuelve una generación atípica, unida por algunos intereses comunes, los propios de quienes quieren sobresalir, y por los de género: mismos problemas, mismos retos. Tienen clara una idea: escribir, difundir su obra, distinguirse dentro de la literatura, y qué mejor manera que haciendo una revista literaria en la que puedan escribir al lado de escritores renombrados y jóvenes talentosos.

Beatriz Espejo explica que coincidió en la Facultad de Filosofía y Letras con los escritores José Emilio Pacheco, Carlos Monsiváis, Gustavo Sainz, José Agustín, Huberto Batis, Salvador Elizondo, José de la Colina, Alberto Dallal, Nancy Cárdenas y Miguel Sabido, 
entre otros. Apunta: "algunos son o eran mis amigos; sin embargo, no compartí un concepto generacional como los ateneístas, los contemporáneos, los espigos o los onderos, por ejemplo" (Espejo, Confiar 42-43). Beatriz Espejo parece haber sacado de sus maestros ese afán perfeccionista, por eso "escribe y corrige hasta el delirio", dice el crítico Emmanuel Carballo (210), y la califica de escritora parca. Carballo (apunte aparte, su esposo desde los años setenta) también afirma que "la literatura femenina en prosa parte de los textos de Guadalupe Amor (más atendible como narradora que como poeta), Elena Garro, Josefina Vicens, Amparo Dávila, Inés Arredondo y Elena Poniatowska". Carballo recuerda que Beatriz Espejo nació en la década de los treinta (1939), década a la que también pertenecen "María Luisa Mendoza, Julieta Campos, Margo Glantz y Maria Luisa Puga (209).

Todas las rehileteras eran mujeres de ciudad y más o menos conservadoras. Aún las más jóvenes habían sido educadas en el seno de familias muy tradicionales, y aunque entre ellas hubiera familiares amantes de la literatura y alguno que otro intelectual, habían sido formadas con los antiguos valores que defendía una sociedad que en general hacía agua. La propuesta transgresora de las rehileteras en este sentido era todavía muy limitada. En ellas prevalecían las buenas costumbres. El uso de la falda y el vestido era riguroso. El arreglo personal aún estaba de moda. Ninguna de las rehileteras fue jipi ni se enlistó en las juventudes que apoyaron la Revolución Cubana. No probaron drogas. El matrimonio era todavía una institución respetable. El divorcio aún era mal visto y poco practicado. Tampoco participaron -ni lo mencionaron en la revista- en el movimiento de 1968.

Pero las rehileteras sí fueron transgresoras, esto por ser diferentes, como parte de una nueva burguesía. Estaban inmersas entre la clase media alta y una riqueza sin excesos. Beatriz Espejo venía de estudiar toda la vida en colegios de monjas, pero se divorció al poco tiempo de haber contraído matrimonio y volvió a casarse (Espejo, Confiar 27). Elsa de Llarena se había divorciado. Carmen Rosenzweig se atrevió a adoptar a tres hijos sin casarse. 
Ninguna del directorio era extranjera. Aunque sí se publicaron a escritores y pintores extranjeros. Por supuesto que las rebileteras tuvieron enlaces con otros escritores, artistas, intelectuales y políticos de la época.

Aunque El Rebilete fue una revista concebida y editada en la Ciudad de México, su interacción con los círculos intelectuales hegemónicos, cuya sede estaba en la Ciudad de México, le dio tal prestigio que, de algún modo, la convirtió en una revista nacional. En ese momento, los productos artísticos e intelectuales que se hacían en la Ciudad de México, de recibir el apoyo de esa élite y debido al centralismo, se volvían de interés nacional. El parámetro del comportamiento urbano residía en la gran capital, cuya radiografía personal ya para entonces había elaborado Carlos Fuentes. El escenario, la colonia del Valle, la Narvarte, Chapultepec, Ciudad Universitaria. La casa de Elsa de Llarena, donde se realizaban las reuniones de las rehileteras, estaba en Patricio Sanz número 21, casi esquina con el viaducto Miguel Alemán, en la parte central de la ciudad, a un par de cuadras del principio de Insurgentes Sur y al otro lado de la colonia Roma. Hay que recordar que en esa época el tradicional centro cultural de la ciudad se había empezado a mover hacia el poniente y sur de la ciudad, y que la población de la ciudad crecía: en una década pasó de 5,2 millones de habitantes en 1960, a 8,9 millones, en 1970 (Hamnett y Martínez 286).

Beatriz Espejo, Margarita Peña y Lourdes de la Garza eran casi vecinas, Blanca Malo vivía en avenida Cuauhtémoc y Carmen Rosenzweig en Mixcoac. Las reuniones se realizaban en las tardes, empezaban como a las cuatro, unas las llamaban encerronas, otras simples reuniones de trabajo que debían terminar temprano, porque antes de las nueve de la noche las respetables señoritas que participaban debían estar en sus casas.

La casa de Elsa de Llarena, quien era divorciada y vivía solamente con su hijo Antonio, era un espacio para las rehileteras en el que podían expresarse con libertad y estar a sus anchas. Un lugar hermoso, bien ambientado, pero principalmente un sitio apropiado para hacer cultura. 
La primera época (números 1-16, abril de 1961 a marzo de 1966) mantuvo casi completo al grupo original y procuró sostener cierto equilibrio entre textos de creación y de análisis. La participación de las rehileteras alcanzó su mejor momento, la mayoría de los textos que se registran de ellas se dan en este periodo. Participan con textos de ficción, poemas, comentarios, reseñas, ensayos. Están todas y todas participan. Su trabajo conjunto se observa en el resultado, se obtienen textos de maestros y escritores renombrados o amigos, se privilegia a las nuevas generaciones de autores mexicanos, se insiste en la calidad como espíritu de la revista.

En la segunda época (números 17-29, de septiembre de 1966 a diciembre de 1969), las tres rehileteras sobrevivientes (Carmen Rosenzweig, Elsa de Llarena y Carmen Andrade, y desde marzo de 1967, también Margarita López Portillo) tratarán de mantener al barco flotando. Aparte de tener en común con la primera época, que estén ellas tres, y mantener en general el mismo tamaño y formato de la revista, se notan los cambios en la selección de los materiales y los autores. El trabajo que hacían diez ahora lo tienen que realizar tres. Por eso resulta muy justificable la presencia de Margarita López Portillo en el grupo. Necesitan recursos humanos y relaciones. Un punto que en esta época se descuida es el análisis. $\mathrm{Al}$ hacer el balance, comparativo en el número de reseñas y ensayos publicados en la primera época con la segunda, descubrimos que son muchos menos los textos de análisis y comentario. No queda claro lo que pasa, quizá la salida del grupo universitario (Espejo, Peña, Malo) afecte este renglón.

La tercera época (números 30-36, de abril de 1970 a abril de 1971) fue dirigida por Elsa de Llarena y Carmen Rosenzweig, con un consejo de redacción formado por dos jóvenes poetas, Mariano Flores Castro y Mario del Valle, quienes en el último número, como dije antes, por primera, última y única vez se integraron a la directiva. En esta última época sale definitivamente la parte de análisis, ensayo casi no se publica. El contenido de estos números difiere en mucho de los primeros. Se ausentan varias plumas, aunque en el último número se reúnen un gran número de los intelectuales de fines de la década. 
Dentro de la revista se publicaron 327 diferentes autores, entre escritores y artistas plásticos contemporáneos mexicanos y extranjeros, y algunos autores y pintores de otras épocas y de otros países en cierto modo calificados como clásicos.

Entre los contemporáneos se pueden agrupar a personas con determinado prestigio en ese momento, a jóvenes que empezaban a destacar y algunos que habrían de despegar algunos años después y, en un tercer grupo, a gente que con el tiempo desaparecería de las letras.

Entre los primeros se encuentran Ermilo Abreu Gómez, Antonio Alatorre, Carmen Alardín, Manuel Alcalá, Griselda Álvarez, Juan José Arreola, Rubén Bonifaz Nuño, Juan de la Cabada, Emmanuel Carballo, Dolores Castro, Rosario Castellanos, Guadalupe Dueñas, Salvador Elizondo, Carlos Fuentes, Emma Godoy, Enrique González Rojo, Efraín Huerta, Luis Leal, José Luis Martínez, Marco Antonio Millán, Salvador Novo, Margarita Paz Paredes, Jaime Sabines, Rafael Solana, Julio Torri, Edmundo Valadés, Agustín Yáñez y Francisco Zendejas.

En el segundo grupo sobresalen los nombres de René Avilés Fabila, Elsa Cross, Humberto Guzmán, José Agustín, David Huerta, Homero Aridjis, Alejandro Aura, Federico Campbell, Marco Antonio Campos, Alberto Dallal, Carlos Monsiváis, José Emilio Pacheco, Gustavo Sainz, Esther Seligson, Jaime Augusto Shelley, Juan Tovar, Tomás Mojarro, Sergio Pitol, Eduardo Elizalde, Marco Antonio Montes de Oca, Juan García Ponce, Vicente Leñero y Elena Poniatowska.

Además, se incluyeron traducciones y textos de escritores extranjeros: Edward Albee, Rodolfo Alonso, Jerzy Andrzejewski, Gonzalo Arango, Max Aub, Ambrose Bierce, Michel Butor, Ernesto Cardenal, Lawrence Ferlinghetti, Kierkegaard, D. H. Lawrence, Ernesto Mejía Sánchez, Augusto Monterroso, Henri Michaux, Ezra Pound y Marcel Schwob.

Asimismo, colaboraron pintores, diseñadores, cineastas, dramaturgos y las mismas editoras, quienes como autoras también participaron con relatos, poesía, editoriales, reseñas, comentarios, traducciones y crítica literaria. 
También hay algunos escritores e intelectuales españoles exiliados. Entre ellos están Elvira Gazcón, Max Aub, Ramón Xirau, Tomás Segovia, Angelina Muñiz, Mada Carreño, Simón Otaola, María Dolores Arana, María J. Embeita, Juan Rejano y Luis Rius.

Llama la atención que entre esos 327 autores estén ausentes algunos importantes de esa época, como Huberto Batis y Margo Glantz, entre los jóvenes. Elena Garro, Inés Arredondo y Amparo Dávila, entre las mujeres que ya destacaban; o Rufino Tamayo, entre los artistas.

La omisión de estos autores parece obedecer a razones distintas a la exclusión por odio o por diferencias intelectuales. Menciona Beatriz Espejo (entrevistada por mí) que ella le pidió un texto a Inés Arredondo, pero ella no quiso dárselo, porque le explicó que además de escribir poco, buscaba publicar donde le pagaran. Sin embargo, recuerda que otros escritores simpatizaban con el proyecto porque veían a mujeres decididas e inteligentes, que daban mucho para que la revista saliera adelante. Ese fue el caso de Carlos Pellicer, quien aceptó entregarles una colaboración, a pesar de que solía publicar solamente donde le pagaran.

Entre los principales ejes temáticos pueden advertirse los siguientes:

Preferencia marcada por la literatura extranjera y lo extranjero. Ello obedece al interés que prevalecía entre los escritores citadinos de la época por considerarse con conocimiento e insertos en las tendencias y prácticas literarias contemporáneas, o, seguidores o adeptos de esas prácticas. Era muy obvio, sobre todo en el caso de autores europeos, que aquella exhibición pública sirviera para subrayar las ideas, influencias y paternidades literarias que guiaban su camino. Aparte, estas publicaciones daban a conocer entre sus lectores las novedades y tendencias más o menos recientes. Realmente, esta estrategia no era nueva, se había llevado a cabo en el siglo XIX y aún antes; en el siglo XX los estridentistas y los contemporáneos también la habían puesto en práctica. Esta presencia de lo de afuera se da en dos vertientes, de manera directa, mediante la publicación de autores extranjeros, principalmente europeos, aunque hay también norteamericanos, orientales y sudamericanos. No obstante que solo un 25 por ciento de 
los autores publicados son extranjeros, la mayoría de los materiales publicados son sobre autores de otros países.

Crítica literaria. El análisis y revisión de textos a través de reseñas y ensayos es una preocupación constante que se expresa en la revista con mayor énfasis en la primera y segunda época, mientras que en la tercera este eje temático casi desaparece. Ya sea de lo extranjero o de lo nacional, las opiniones fluyen con agudeza y generalmente buen tino. No hay pifias de las que arrepentirse. La mayoría de las rehileteras son muy cautas, o un poco menos que tibias, en sus juicios. Las más ásperas son Rosenzweig, Peña y Llarena.

Lo último de la producción literaria. Como una revista literaria de actualidad, El Rebilete publica muestras de la producción que estaban realizando los escritores invitados, fueran de maestros ampliamente reconocidos, de plumas que aún se esforzaban por despuntar o de jóvenes promesas. De estos dos últimos grupos, en lo publicado no se observa con claridad una subversión de las formas literarias tradicionales ni temática ni estructuralmente. Es cierto que hay esfuerzos, pero no se observa esa ruptura radical que aparentemente se da entre una y otra generación.

Autoridad literaria. Aunque no es propiamente un tema, publicar a varios maestros o escritores reconocidos se convirtió en un eje por sí mismo. A este eje temático lo llamo "autoridad literaria". Se busca, principalmente en la primera época, publicar a estas autoridades literarias de aquellos años, gente con un prestigio consolidado, personajes que se habían hecho en el sistema literario mexicano, por sus estudios o por sus creaciones. Este criterio de selección supuso que las rehileteras pusieran en práctica su talento para convencer, para obtener colaboraciones, para transmitir su entusiasmo, para explotar su simpatía, acaso para contagiar su vigor juvenil y su amor por la literatura entre sus maestros. Esto es importante subrayarlo, principalmente ocurre en la primera época, cuando la revista empieza, y el espacio debe acreditarse y hay desconfianza en los resultados. Cuando se consolida, este trabajo de obtención de materiales se vuelve más fácil, aunque siempre esté presente, sobre todo, considerando, que salvo dos números, el dedicado a los siete pecados capitales (número 22) y en el de las virtudes teologales 
(número 25), en los que se pagaron 500 pesos a cada colaborador, en los demás no se pagó nada por colaboración. Ciertamente, la presencia de estos escritores reconocidos (incluso póstumamente, como Alfonso Reyes y Efrén Hernández) atraerá lectores y consolidará un prestigio, bajo cuyo cobijo se arroparán nombres desconocidos o aún sin gran reconocimiento. Así, en el primer número las cartas fuertes son Guadalupe Dueñas, Ermilo Abreu Gómez, Efrén Hernández, Rubén Bonifaz Nuño, Emma Godoy y Francisco Monterde. En los demás números se sumarán otros nombres: Ramón Xirau, Luis Rius, Tomás Segovia, Agustín Yáñez y Antonio Alatorre, quien presenta un texto de evidente corte académico.

Teatro contemporáneo. En El Rebilete fueron publicados varios textos sobre teatro; fueran creaciones o textos de análisis, de crítica, en la primera época, principalmente, se nota la presencia del teatro. Entiendo que ello podemos atribuirlo, como se observa, a la colaboración de una promotora del teatro contemporáneo de aquella época: Nancy Cárdenas, activa veinteañera que trabajaba en radio y había participado con Héctor Mendoza en Poesía en Voz. Alta. Mujer inquieta y vigorosa, que lo mismo actuaba, dirigía y traducía, como se observa en lo publicado. El mejor ejemplo de esto se halla en el número seis (1962), que publica la pieza "Picnic en el frente de batalla", de Fernando Arrabal.

Revolución y esperanza. Aunque en la revista se huye del tema político, hay textos que hablan de revolución, de cierto compromiso social, esperanza, optimismo por un mundo distinto, indignación por lo que está mal en el mundo, grito de protesta. Ciertamente, las editoras de El Rehilete nunca externaron una posición política explícita en la revista. Si bien al callar sobre los sucesos del 68, incluida la misma Olimpiada -omitirlo absolutamente de la revista- definieron una postura: mantenerse neutras ante un hecho $-\mathrm{y}$ ante todos los acontecimientos políticos-, que según mi opinión exigía al menos lamentar las muertes y la violencia. Se empeñaron en demostrar que el trabajo literario estaba al margen de los sucesos políticos e históricos del país y del mundo. Porque igualmente nunca se manifestaron a favor o en contra de la Revolución Cubana, tan de moda en ese entonces. No hay referencia alguna a Casa de 
las Américas, ni al concurso ni a la revista. Al contrario, publican a un cubano que se había refugiado en Estados Unidos: José Kozer. O publican inserciones de actividades oficiales, incluida la mención del presidente Gustavo Díaz Ordaz en uno de ellos. Aunque no se mencionen (o apenas) nombres, lugares y situaciones específicas, se observa el interés de algunos colaboradores de denunciar, exigir, consignar un deseo por un mundo más justo.

Mujer. En muchos de los textos escritos por mujeres es la propia mujer el eje temático. Lo más interesante es que los personajes femeninos no son víctimas, más bien son mujeres que han tomado las riendas de su vida o están a punto de hacerlo. Principalmente los textos escritos por las editoras, Carmen Rosenzweig, Beatriz Espejo, Elsa de Llarena, versan alrededor de la mujer, parecen casi confesiones sobre ellas mismas y sus circunstancias y problemas.

Una revista literaria lo es porque es espacio para la literatura, es decir, se concibe con propósitos que podríamos calificar específicamente como literarios: difundir la creación literaria actual, publicar reflexiones y análisis sobre la producción contemporánea, cercana o incluso remota, publicar entrevistas, hablar de libros y de escritores, divulgar la literatura, y algunos otros propósitos que seguramente se me escapan. El cumplimiento de estos objetivos estará sujeto a la recepción que se logrará entre los lectores, en los ámbitos (cultural, literario, universitario, general) en los que se desenvuelve, y a las características del proyecto.

El trabajo editorial de las rehileteras contribuye a consolidar las ideas y los principios generales de una élite intelectual predominante, que se inclinaba por modelos literarios extranjeros, que era cosmopolita y citadina, que buscaba la modernidad. Aunque su espacio aglutina a escritores de diferentes tendencias y edades que en ese momento alternan en la literatura mexicana, sus páginas recogen el canon literario de la época, empatan, se afianzan en los principios generales de esta élite intelectual, cuyos representantes, o algunos de ellos, son publicados en la revista o son mencionados en ella, con el fin de equipararse con las revistas que esa élite reconocía. De este modo, comparten con ese grupo el prestigio de ser canon intelectual y literario de una sociedad cuyo centro cultural hegemónico era la 
Ciudad de México. Esa era la importancia de editar y distribuir una revista desde una colonia, en este caso la del Valle, del centro urbano tradicional que eligió la mencionada clase intelectual.

Las editoras, en ningún momento intentan excluirse, oponerse, objetar, contestar o contradecir el canon y a quienes lo ostentan. Esta actitud las subordina, o simplemente las incluye, a ellas y a la revista, como parte de un hecho cultural de la época. La ruptura habría significado aislarse, marginarse, ser un alternativa que se opusiera a dicho canon literario, a la idea literaria hegemónica, que ya tenía sus representantes, que ya había establecido nombres, obras, tendencias, acordes, además, al mismo canon que se imponía desde las literaturas de los países que servían de modelos: Francia y en general Europa, y los Estados Unidos. La revista no es un campo de pruebas, no es un laboratorio para experimentos de ningún tipo, por sí misma la revista es un experimento que fructifica. Ciertamente se publican algunos textos que experimentan con formas, pero no prevalece ese espíritu a lo largo de la existencia de la revista. Beatriz Espejo habla de que la revista fue un espacio para la experimentación, pero ello asume esto en el terreno del aprendizaje como editoras, no como escritoras. Confiesa que para ella la revista fue un taller para ejercitarse:

Tuve la idea de una revista literaria cuyo directorio estaría integrado por mujeres. Con la ayuda principalmente de Elsa de Llarena, Carmen Rosenzweig, Carmen Andrade, Lourdes de la Garza, he conseguido sacar El Rehilete con altas y bajas y casi de milagro en medio de constantes apuros económicos; sin embargo, para mi propia formación tal aventura constituye un buen aprendizaje, siempre me resulta conveniente inventarme compromisos que me pongan a escribir (Flores 19).

Por lo demás, la revista El Rebilete se ofrece como una alternativa para publicar, un espacio creado por las propias editoras para difundir sus textos. Es una revista acreditada por escritores reconocidos, aceptada como suya por la élite intelectual mexicana. Es un espacio abierto para la buena literatura. 
No hay que soslayar que el reconocimiento público también es una motivación que impulsa, sobre todo a los jóvenes, ávidos de establecer su presencia física en un medio determinado, de pasar a la acción. Y qué mejor forma de hacerlo que publicando una revista independiente, que no tenga las acotaciones establecidas en una revista institucional, que permita la libertad para crear, para decidir, para hacer, para sobresalir. Destacar en el mundo literario como un personaje protagónico ha animado a más de uno. Beatriz Espejo lo precisa muy bien cuando reconoce que el ejemplo, la notoriedad y quizá también la fama de Ramón López Velarde la impulsaron un día a promover la creación de la revista. A esta motivación se le considera banal, inferior, por eso pocas veces se le reconoce abiertamente. Hacer una revista para adquirir fama. Sin embargo, en el fondo siempre está presente en aquellos esfuerzos que no tienen un pago material de por medio. Además, este tipo de proyectos significan un reto, una prueba que evidencia capacidades y también limitaciones, una forma de demostrar al mundo lo que se puede hacer, y por lo que se es valioso. Quizá por ello, esfuerzos como el de El Rehilete forman parte de las primeras actividades consignadas en la trayectoria literaria de casi todo escritor. Hacer una revista da prestigio y genera relaciones y amistades.

Y no obstante lo anterior, para las editoras El Rehilete nunca fue el proyecto más importante de sus vidas. Beatriz Espejo y Margarita Peña se dedicaban a sus estudios universitarios. Carmen Rosenzweig trabajaba en una empresa privada, de la cual obtenía los ingresos que le daban manutención, y durante esta época fue cuando decidió convertirse en madre soltera adoptando a tres hijos, pese a trabajar todos los días de nueve de la mañana a cinco de la tarde (Poniatowska 2011).

Eso también explica por qué el propósito material nunca estuvo presente, aunque la edición siempre se desarrolló entre problemas materiales, principalmente por lo que significaba conseguir los recursos para imprimir la revista. Suficientes problemas como para impedir la realización de un suceso lógico en el desarrollo de este tipo de proyectos: la edición de libros. El Rebilete no publicó plaquetas ni libros. 
Igualmente se pretende promover la literatura contemporánea y ser parte de ella. Por ello se da cabida a diversos géneros, a escritores de diferentes edades y reconocimiento, a temas y nacionalidades. No obstante, su intención no es consignar una realidad como un objeto sociológico, o como un proyecto que registre la cultura en general, como lo intentaría Octavio Paz con Plural y Vuelta. Su idea de lo contemporáneo es lo presente, su presente (quizá acordes con el ejemplo dado por Juan José Arreola en su colección Los presentes), es lo de hoy porque existe, sin relación a una ideología política. Con una actitud que se distanció de casi todos los acontecimientos externos a la literatura. Presentan un mundo contemporáneo acotado a lo literario, donde se omite lo político (salvo las inserciones pagadas) y los hechos históricos están ausentes casi por completo; las editoras convierten a la revista en una isla, dentro de la cual, solo hay escritores y textos, análisis y reflexión, evocaciones y sobre todo, palabras, la única realidad, el único presente. Ello explica la falta de datos históricos, la ausencia de cualquier mención directa al movimiento estudiantil y social del 68, incluida la masacre de Tlatelolco, por eso esa ausencia de información que relacione ese tiempo literario con los otros acontecimientos de la realidad. Por supuesto que la intención es hacer literatura por la literatura, ser absolutamente universal, estar dentro de lo contemporáneo, crear una revista literaria que apenas toque el tiempo real, con pocas fechas precisas, sin la conexión que tiene el periodismo con los sucesos diarios, una publicación que no tiene compromisos extraliterarios. Las editoras se sienten orgullosamente parte de un universo literario ajeno a la realidad que ellas aseguran, en el editorial del primer número, debe reflejar el arte:

La verdadera creación literaria se alimenta de todas las realidades, las trasciende, y sobre el valor social o político que contenga, subsiste por la identificación que nos sugiere de gestos, actitudes, aconteceres, en un corte de profundidad que permanece (5). 
Esta exclusión tiene una motivación elitista, que considera a las actividades artísticas como prácticas superiores, porque están por encima de nombres, lugares y sucesos cotidianos.

Por otra parte, El Rebilete no intentó ser una respuesta explícita a ninguna carencia de la literatura mexicana de aquella década. Como El Rehilete había otras revistas literarias, muy parecidas en el formato, diseño, en el tipo de papel y en la estructura. Las más parecidas eran Ábside y Lapalabra y el hombre. Esto se explica de manera muy simple: las editoras buscaban tener una revista literaria muy similar a otras porque deseaban que fuera precisamente similar a esas otras, la intención era confundirse con las revistas que tenían ya cierto reconocimiento, como La palabra y el hombre, de ningún modo diferenciarse.

Por los colaboradores, las temáticas y materiales publicados, tampoco puede decirse que El Rebilete haya sido el órgano de difusión de ningún taller, de un club o de una institución específica. Ciertamente, la revista concentra una etapa de la vida literaria de nuestro país, y es orientada por un grupo de mujeres con determinadas características culturales, producto de la sociedad de esa etapa, pero no está acotada, al menos no explícitamente, a un grupo específico de la sociedad, sea este dado por una organización, un rango de edad, un currículum, una nacionalidad o un género. No es una revista estudiantil, aunque en ella participen estudiantes; no es feminista, aunque la editen solo mujeres.

El Rebilete no pretende ser una revista para escandalizar ni para sacudir a la República de las Letras; el que la hicieran solo mujeres no fue para hacer temblar a nadie, únicamente quisieron aprovechar sus talentos como mujeres de esa época, y hacer una revista literaria que fuera considerada por los lectores como una "buena" publicación, como otra de las que entonces circulaban en el país.

Y no obstante de conjugar los intereses de varias mujeres, igualmente se podría decir que en el fondo la revista es un proyecto personal (el de Beatriz Espejo o el de Carmen Rosenzweig) que se oculta debajo de la piel de un grupo. Sin embargo, ambas tuvieron que compartir el crédito. Una considera que lo inició, como inspiradora de la idea; la otra, como quien lo mantuvo vivo, contra 
viento y marea, y lo terminó cuando el proyecto fue alcanzado por el agotamiento.

Los juicios antes vertidos están sustentados en general en lo contenido en la revista, así como en lo expresado por las editoras en entrevistas y escritos. Sin embargo, en los editoriales publicados se observan mejor estas ideas, conceptos, motivaciones, intereses y propósitos. El análisis de las afirmaciones y definiciones contenidas en estos igualmente hace evidente contradicciones y carencias, omisiones y cierta confusión producto de un estilo a veces tan oscuro y figurado, que opaca los significados con anfibologías, metáforas y una sintaxis difícil.

Hay un propósito de género que no se reconoce, aunque esté presente en el proyecto, desde su concepción hasta el último número. La revista nunca se asumió como la publicación de un grupo, nunca como la voz de una organización comprometida con una doctrina, nunca como una causa feminista. Incluso este término está prácticamente ausente en los 36 números editados.

$\mathrm{Al}$ preguntársele si El Rehilete era una revista feminista, Beatriz Espejo lo ha dejado claro:

No lo era en sentido militante. Se trataba de un feminismo intuido en el cual todavía creo, la preparación y superación académica de las mujeres, la remuneración económica (aunque nunca pudimos pagar colaboraciones, salvo en un par de números antológicos sobre los pecados y las virtudes capitales), el éxito personal que conjugue el trabajo y permita la independencia (Confiar 36).

Esta declaración, por supuesto, está construida desde la perspectiva que da el tiempo, cuando lo ocurrido se objetiva y se analiza nuestro comportamiento con los conocimientos y la experiencia adquirida. Esta explicación las acerca hoy a la causa de las mujeres, hoy, cuando esa causa tiene tal fuerza que difícilmente admite desprecios abiertos de las propias mujeres, y aún menos de los hombres.

Cuando le dicen a Beatriz Espejo que si ella y Margarita Peña abrieron camino a las mujeres dentro del campo editorial afirma: 
"De alguna manera es cierto. El Rehilete fue una revista vanguardista; sin embargo no fue la primera exclusivamente hecha por mujeres. Antes había salido Rueca, a finales de los cuarenta. Pero, como afirma Sor Juana, una puerta abre otra" (Arenas y Olivares 43). Y explica:

Redactaba mi tesis de maestría -me recibí muy pronto- y por influencia de López Velarde quise lanzar al aire una publicación que sirviera como laboratorio experimental para jóvenes. Esa misma noche llamé a Margarita Peña y ella concertó el grupo. Nos entregamos a la tarea con un ímpetu increíble. El Rehilete salió diez años. La dirigí en muchos números. Los dos últimos fueron casi unos libritos, sobre los siete pecados capitales y las siete virtudes teologales. Los ilustraron respectivamente José Luis Cuevas y Froylán Ojeda, que en esa época sonaba y que murió sin haber dado el estirón que se esperaba de él... Los meses anteriores a que saliera El Rehilete, anduvimos pidiendo consejo a nuestros maestros y amigos. Recurrimos, claro, a las antiguas integrantes de Rueca. María del Carmen Millán trató de quitarnos la idea pensando que no sacaríamos ni dos números. Helena Beristáin, por el contrario, nos animó con esa generosidad que la caracteriza. Desde entonces somos grandes amigas... (43)

Por su parte, también sobre el tema del feminismo de El Rebilete, Dionicio Morales apunta: "Recuerdo que un poco más adelante se reunió un grupo de mujeres, escritoras todas ellas - por cierto visto con un poco de recelo por los escritores de la época, quienes sonreían de incredulidad-para formar una revista que se llamó El Rebilete..." (64). A lo que contesta Nava con mucha contundencia:

Te aclaro que ninguna de las mujeres integrantes de El Rehilete éramos feministas. La dirigía Beatriz Espejo y nuestro objetivo no era hacer algo por mujeres para publicar solamente a mujeres; estaba abierta los hombres, a todos los grupos, a todas las tendencias. Mi participación fue por muy corto tiempo debido al inicio de la publicación de Pájaro Cascabel (64). 
No fue un "feminismo intuido", porque lo intuido es un conocimiento o una acción que se asume conscientemente, aunque no se advierta su origen. En términos filosóficos generalmente se admite a la intuición como un conocimiento ajeno a la razón, y el cual, para darse, requiere de un sujeto y de un objeto, que sirve a este sujeto para obtener la experiencia de la intuición. Y las mujeres que participaron en El Rebilete no se asumieron como feministas, no advirtieron ese conocimiento por la vía de la intuición. Yo prefiero calificarlo como un "feminismo ejercido". Término que utilizo en dos sentidos, primero como práctica de "formas de comportamiento atribuidas a una determinada condición”, como lo señala el Diccionario de la Real Academia Española, y segundo como el hacer uso de un derecho, el derecho a participar en el mundo con un trato equilibrado, y bajo las mismas oportunidades, como el que exigió en los sesenta Betty Friedan (2009). Y ejercieron un feminismo, aunque no lo admitieran, cuando ingresaron a espacios y prácticas que solo se permitían a los hombres, o que ellos únicamente consideraban ser capaces de ejercer, como si fuera un derecho exclusivo, un privilegio que no era permitido para las mujeres. Por eso no es extraño encontrar, por ejemplo, a Margarita Peña como una de las fundadoras de la revista Fem, una publicación que sí fue abiertamente feminista y exclusiva para mujeres. Igualmente, la misoginia, o el hacer a las mujeres a un lado, era un hecho que rara vez se admitía en público, abiertamente, pero que estaba implícito detrás de frases irónicas o contenidas subrepticiamente en comentarios y actitudes. Referirse a ellas como "las muchachas", como lo hace Huberto Batis (1984 51), o destacar su belleza, como lo hace Carlos Valdés o el mismo Batis, o menospreciar el trabajo de las editoras de la revista, como lo hace Antonio Alatorre cuando publica, en 2003, en la Nueva Revista de Filología Hispánica, por segunda ocasión un ensayo originalmente publicado en El Rehilete. Dice: "En la presente versión hay gran número de materiales, así como notas de pie de página, que omití en 1964, porque El Rehilete no era una revista profesional [Alatorre pone la palabra profesional entre comillas]" ("Un tema" 81). Es evidente que esto último pudo haberse evitado sin que 
ello desvirtuara la información filológica, o se pudo utilizar los adjetivos arbitrada o académica.

Situaciones y palabras que hacían evidente que no se tomaba en serio la decisión de la mujer de participar en todas las actividades técnicas y culturales de la sociedad, es decir, en aquellas distintas a las tradicionalmente asignadas a la mujer en el campo laboral: en la enseñanza o en actividades de apoyo, como ser enfermera o secretaria. Ese fue el entorno que recibió el proyecto editorial de las rehileteras.

Este "feminismo ejercido" implicó afrontar a un grupo de intelectuales y/o escritores que se movían en un ambiente literario e intelectual que sancionaba todas las expresiones artísticas y culturales, admitiéndolas o rechazándolas. La descalificación por ser mujer o por ser homosexual aún estaba muy viva, aunque en los ambientes intelectuales esto no se reconociera. Pocas personas, como Carlos Monsiváis, advirtieron la vigencia de este problema. El machismo persistía entre un gran número de mexicanos, como hoy mismo persiste, así como proseguían vivos los privilegios masculinos, se descalificaba la homosexualidad y se menospreciaba lo escrito por las mujeres. Todo ello, no obstante que la tendencia intelectual asumiera estos asuntos, al menos de dientes para fuera, con mucha comprensión y amplio criterio. Claro que el ninguneo, ignorar, desconocer, eran también formas utilizadas por esta élite para descalificar lo realizado por las mujeres. De esta forma se entienden mejor las críticas que reciben en ese momento, la defensa que hace Rosenzweig en el editorial número dos y los calificativos negativos sobre el mundo literario de ese momento que publican las rehileteras, quienes igualmente se asumen como críticas, como jueces de ese entorno que las sanciona, igualando en actitud y soberbia el mismo mundo que las señala.

Las rebileteras ejercieron el feminismo desde el momento en que decidieron hacer una revista literaria editada solo por mujeres, lo ejercieron cuando se atrevieron a realizar fuertes juicios sobre la literatura mexicana, y también cuando ingresaron a un mundo, el editorial, que era coto de los hombres. Nelly Richards, en el ensayo ¿Tiene sexo la escritura?, explica que hay 
...feminización de la escritura . . c cada vez que una poética o que una erótica del signo rebasan el marco de retención/ contención de la significación masculina con sus excedentes rebeldes (cuerpo, libido, goce, heterogeneidad, multiplicidad, etc.) para desregular la tesis del discurso mayoritario. Cualquier literatura que se practique como disidencia de identidad respecto al mandato reglamentario de la cultura reglamentaria de la cultura masculina-paterna; cualquier escritura que se haga cómplice de la ritmicidad transgresora de lo femenino pulsional, desplegaría el coeficiente minoritario y subversivo (contradominante) de lo "femenino (132-33)".

Y retoma una cita de Diamela Eltit, quien dice que lo femenino es "aquello que desde los bordes del poder central busque producir una modificación en el tramado monolítico del quehacer literario más allá que sus cultores sean hombres o mujeres generando creativamente sentidos transformadores del universo simbólico establecido" (Richards 133).

Este feminismo ejercido va en contra de lo que ellas buscan afanosamente, confundirse con los hombres, ser ellos, actuar como ellos, no distinguirse, no separarse de las figuras masculinas más representativas. Beatriz Espejo reconoce que su ejemplo era Ramón López Velarde, las editoras hablan en sus editoriales como si fueran hombres (dicen "nosotros") o evitan usar algún pronombre que identifique su sexo, aunque debajo del escrito se lea claramente el nombre femenino de la autora.

Igualmente evidencian este feminismo ejercido que las alienta en su proyecto editorial desde el momento en que deciden acceder al espacio público, a ser parte de él, a contar en él igual que los hombres. Un espacio, además, que es muy atractivo porque está lleno de cambios y oportunidades. Buscan en ese ámbito el reconocimiento, la aceptación, por eso la insistencia, en las dos perspectivas diferentes que asumen las cabezas de las rehileteras (Rosenzweig y Espejo), dos visiones que en el fondo tienen un mismo propósito. Mientras Rosenzweig ve con sospecha la literatura producida en México (salvo "una, dos, muy pocas excepciones"), Espejo insiste 
en la necesidad de practicar la buena literatura, de buscar la calidad y la superación permanente. Las dos son estrategias que buscan el respeto, sea por el ejercicio de la crítica, o sea por los resultados evidentes. El respeto se obtiene al demostrar lo que se es capaz de hacer. Al obtenerse el reconocimiento, se logra la igualdad.

Hay una abierta preocupación de parte de las editoras/escritoras de El Rehilete por identificarse, confundirse, incorporarse, sin distinción con los criterios de valoración estética dominantes, que no son otros que los impuestos por una tradición definida por los hombres. De esta manera manifestaron su rebeldía a la hegemonía masculina que relegaba a un segundo plano, con prejuicios, a la literatura hecha por mujeres, considerándola como algo especial por el hecho de que lo hacen mujeres. Su interés por perdurar, por trascender, su protagonismo es una forma de ejercer el derecho a ser igualmente aceptadas en un medio que las desprecia.

La situación que advierto de ningún modo tiene matices relacionados con el tema de la lucha de clases. Las editoras de El Rehilete forman parte de una clase social, entre media y alta, que busca integrarse, no objetar ni confrontar a una élite intelectual. De ningún modo se cuestionan los intereses y la visión de quienes están detrás del desarrollo intelectual y cultural del país. Hay una clase política, sostenida por un partido político y su entramado de poder, en las que ellas encuentran acomodo.

Estas preocupaciones y estos propósitos contrastarán, en aspectos sustanciales, con las intenciones que mueven a Huberto Batis y a Carlos Valdés a crear Cuadernos del Viento, revista que paralelamente se editó y cuyas circunstancias, aunque parecidas, obedecían a intereses y condiciones distintas (Batis, Lo que Cuadernos 1984).

Ellos, ciertamente, también quieren un espacio público, pero su idea es no solo acceder a él, sino marcar en él una huella de proporciones nacionales.

Algunas de las motivaciones expresadas por Huberto Batis, con respecto a la necesidad de crear una revista como Cuadernos del Viento, son las mismas que las sostenidas por las rehileteras. "¿Por qué, si podíamos publicar nuestras páginas en donde nos diera la gana, se nos metió en la cabeza a Carlos Valdés y a mí el deseo irrefrenable 
de crear nuestra propia publicación? (Batis, Lo que Cuadernos 16)" Y esta pregunta la responde con la siguiente explicación:

Una vez al año, en la Revista de la Universidad, podía aparecer un cuento o un poema de cada uno de los escritores jóvenes, lo cual ya era ganancia... Pero escribíamos diez cuentos o más al año, dos o tres al mismo tiempo, y la novela y los poemas y el ensayo largo. Sólo se nos pedían notas bibliográficas, muchas; todas las que hiciéramos eran publicadas; reseñas de cine, críticas de teatro, 50 y 100 pesos, hasta 75 eran buenos, y además se conseguían los libros y pases para los espectáculos. Así, se volvía uno comentarista, crítico precoz por conveniencia y a destajo. Pero, ¿en dónde publicar la obra propia de creación? Teníamos, pues, que tener nuestra propia revista (23).

En el primer editorial de Cuadernos del Viento, se observan los intereses y las preocupaciones respecto de la razón de la revista. Es así como se escribe con toda claridad y sin rodeos:

los escritores mexicanos queremos tratar con aspiración de universalidad los temas nacionales; pero seguimos escribiendo en el aislamiento y padeciendo la incomunicación con las grandes masas de lectores... [Nuestro siglo] nos pide que heroicamente nos dediquemos a las tareas creativas -desde las posturas 'comprometidas' hasta las de 'torre de marfil'-y que conquistemos al gran público, que tiene que existir en nuestro país... Los Cuadernos del Viento recibirán a todos los escritores particularmente a los jóvenes, sin tener en cuenta nacionalidades, credos, actitudes... Los Cuadernos del Viento desean vivir de sus lectores y hacerlos sus únicos jueces, para no comprometer su libertad de acción; su existencia dependerá de ventas directas, suscripciones y anuncios comerciales (39).

Por supuesto que también esto es retórica y buenas intenciones. Los 500 ejemplares que se imprimieron al principio de Cuadernos del 
Viento, o los mil a los que se llegaría posteriormente no alcanzarían nunca a las masas de lectores. Pero de ese tamaño fueron las pretensiones de Cuadernos del Viento: quería encabezar un movimiento nacional, aspirar a crear lectores entre las masas de indolentes, pretender ser punto de quiebre, parteaguas de la cultura mexicana, y no tiene miedo de decirlo, ni esconde en metáforas oscuras sus ambiciosos propósitos.

En ese sentido las editoras de El Rehilete son más realistas y plenamente conscientes de quienes pueden ser sus lectores. Por eso insisten en criticar y descalificar el trabajo literario, por eso hablan de publicar textos de calidad, de buena literatura, de diversidad, de apertura, de mejorar con cada número. Tienen claro quienes juzgarán lo que ellas publiquen, quienes decidirán si dejarán huella, quienes advertirán su presencia, quienes reconocerán su trabajo como mujeres y como "escritores", no como escritoras.

Esta rápida comparación de los propósitos de El Rebilete y Cuadernos del V iento, dos revistas contemporáneas, que comparten espacios (zonas de la ciudad, ámbitos culturales) y tienen colaboradores en común, evidencian, sin embargo, dos posturas culturales muy distintas, producto de una situación de género, de una condición histórica. La seguridad masculina, frente a la cautela femenina; dos visiones, dos contornos distintos, emparentados por dos palabras: revistas literarias. Espejo lo reconoce cuando asegura que Batis y Cuadernos del Viento eran más abiertos con los colaboradores, en tanto que ellas buscaban ser más elitistas y cerradas.

El Rebilete, de manera formal y en su contenido, es una publicación similar a otras que se editaron al mismo tiempo. Sus colaboradores y artistas plásticos también participaban en las otras publicaciones periódicas, cuyo conjunto se insertaba dentro de las tendencias literarias de la época, y cuyo canon lo definían publicaciones como la Revista Mexicana de Literatura, la Revista de la Universidad y el suplemento cultural La cultura en México, del periódico Novedades (después México en la cultura).

Si bien El Rehilete fue el producto de un grupo de mujeres, no es una publicación exclusiva para publicar a mujeres o para ser dirigida por mujeres. En sus páginas se publican a más cola- 
boradores masculinos que femeninos. De los 327 autores, entre escritores y artistas plásticos, 244 son del sexo masculino $(74.84 \%)$ y 83 del sexo femenino (25.46\%). Sin embargo, de los 829 materiales publicados, entre textos e imágenes, 452 corresponden a los hombres (54.53\%), 337 a las mujeres (40.65\%), y solo $40(4.82 \%)$ no precisan autor. Esto advierte que los materiales elaborados por los hombres no superan por mucho a las colaboraciones de mujeres. Esto se explica por el hecho de que las editoras contribuyen con muchos de los materiales publicados. De las 83 mujeres publicadas, 9 (el 10.84\%) forman parte del directorio de El Rehilete y realizan más de la mitad de las colaboraciones producidas por el género femenino: $55.20 \%$. Con relación al total de lo publicado, su trabajo representa el $22.44 \%$.

Es decir, nueve mujeres $(2.76 \%$ del total de colaboradores) fueron las autoras de un poco menos de la cuarta parte de los materiales publicados en la revista, además de editarla, diseñarla, reunir materiales, distribuirla y administrarla.

La revista publicó principalmente poesía y narrativa. En menor número, se publicaron ensayos, entrevistas, crónicas y otros materiales. En la primera época se publicaron el mayor número de reseñas y comentario de libros.

No obstante el análisis realizado, es posible ahondar en la recepción de la revista, continuando el estudio con metodologías comparativas, que integren a otras publicaciones similares de la época, y permitan obtener resultados claros de los alcances de estas publicaciones en el sistema literario mexicano. Principalmente considerando que entonces se imprimían no más de mil ejemplares en su mejor momento, en un país que ya entonces era de varios millones.

Igualmente, sería interesante ahondar en el análisis, de los sentidos contenidos en los editoriales, ensayos y reseñas de las rehileteras, lo cual, seguramente, reforzará el sesgo de género contenido en el esfuerzo de las rebileteras, y lo integrará con las otras publicaciones de la época. 


\section{Obras consultadas}

Adorno, Theodor W. Teoría Estética. Madrid: Akal, 2004.

Alatorre, Antonio. "Un tema fecundo: las encontradas 'correspondencias". Nueva Revista de Filología Hispánica 101. (2003): 81-146.

Arenas Monreal, Rogelio y Olivares Torres, Gabriela. La voz a ti debida, Conversaciones con escritores mexicanos. México: Universidad Autónoma de Baja California; Plaza y Valdés, 2001.

Batis, Huberto. Lo que Cuadernos del Viento nos dejó. México: Diógenes, 1984.

- Por sus comas los conoceréis, México: DGP; Conaculta, 2001.

Carballo, Emmanuel. Ensayos selectos: México, Universidad Nacional Autónoma de México, 2004.

Editorial. El Rebilete 1: 5. Impr.

Espejo, Beatriz. De cuerpo entero. México: UNAM; Corunda, 1991.

- Confiar en el milagro: entrevista con Beatriz Espejo. Colima: Universidad de Colima, 1998.

Flores, Ángel. Narrativa Hispanoamericana, 1816-1981: La generación de 1939 en adelante. México: Siglo XXI, 1985.

Friedan, Betty. La mistica de la feminidad. Madrid: Cátedra, 2009.

Hamnett, Brian R. y Carmen Martínez Gimeno. Historia de México. México: Akal, 2001.

Morales, Dionicio. Reencuentros. México: UNAM; Coordinación de Difusión Cultural, 1990.

Poniatowska, Elena. "La gran valentía de la escritora Carmen Rosenzweig”. La Jornada 4 septiembre 2011, Cultura: 28.

Richards, Nelly. Masculino/Femenino. Prácticas de la diferencia y la cultura democrática. Santiago: Francisco Zegers editor, 1993.

\section{Hemerografía}

El Rebilete, 1961-1971, México.

Cuadernos de Viento, 1960-1967, México. 